\title{
Application of 2-Chloro-7-Nitrobenzo-2-Oxa-1, 3-Diazol (NBD- CL) for Spectrophotometric Determination of Finasteride in Pharmaceutical Formulation
}

\author{
Sally Mohammed Ahmed ${ }^{1}$, Abdalla Ahmed Elbashir ${ }^{1 *}$, Younis Mohamed Elhassan ${ }^{2}$ \\ ${ }^{1}$ University of Khartoum, Faculty of Science, Chemistry Department, Khartoum, Sudan \\ ${ }^{2}$ University of Medical Sciences and Technology, Khartoum, Sudan
}

\begin{abstract}
A simple, sensitive and validated spectrophotometric method for the determination of finasteride using 2-Chloro-7-nitrobenzo-2-oxa-1, 3-diazol (NBD-CL) has been developed. The method is based on the reaction of finasteride and NBD-CL at alkaline medium ( $\mathrm{pH}$ 11.0) to develop a deep brown adduct that bears maximum absorption at $467 \mathrm{~nm}$. Beer's law is obeyed in the concentration range $25-75 \mu \mathrm{g} / \mathrm{mL}$ of finasteride at the selected wavelength. Under optimized reaction conditions, the linear regression equation of the calibration curve is $y=0.010489524 x-0.012190476$ with a linear regression correlation coefficient of 0.999. The limit of detection (LOD) and limit of quantification ( $L O Q$ ) were found to be $0.17 \mu \mathrm{g} / \mathrm{mL}$ and $0.52 \mu \mathrm{g} / \mathrm{mL}$ respectively. The method has been successfully applied to the determination of finasteride in pharmaceutical formulation.
\end{abstract}

Keywords: Finasteride, spectrophotometric, pharmaceutical formulation, method validation, NBD-CL

Abbreviations: LOD: Limit of Detection; LOQ: Limit of Quantification; FNS: Finasteride, NBD-CL: 2-Chloro7-nitrobenzo-2-oxa-1, 3-diazol; DHT: Dihydrotestosterone; BPH: Benign Prostatic Hyperplasia; GC: GasChromatography; GC-MS: Gas Chromatography-Mass Spectroscopy; HPLC: High Performance Liquid Chromatography

\section{INTRODUCTION}

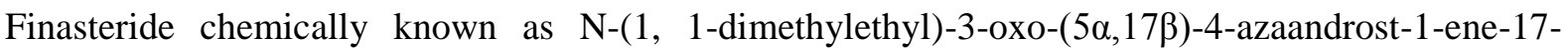
carboxamide is an antiandrogen which acts by inhibiting $5 \alpha$-reductase, the enzyme that converts testosterone to dihydrotestosterone (DHT) [1]. It's widely used for the treatment of benign prostatic hyperplasia (BPH), prostate cancer, and androgenetic alopecia [2-7]. Literature survey reveals that various methods have been reported for the analysis of finasteride in pharmaceutical preparations and biological samples such as gas-chromatography (GC) [9], and (GC-MS) [10] High Performance Liquid Chromatography (HPLC) with various detectors [11-13], polarography [14], voltammetry [15] and spectrophotometry [16-18].

In recent years, stringent quality control in the pharmaceutical industries has given rise to a growing need for simple, selective and sensitive analytical methods for their determination in pure and in dosage forms.

Spectrophotometry is considered the most convenient analytical technique, because of its inherent simplicity, low cost, and wide availability in most quality control laboratories. Only few spectrophotometric methods were reported for determination of finasteride in pharmaceutical formulation [16-18] however, some of these methods were associated with some major drawbacks such as laborious multiple extraction steps in the analysis by ion-pair based methods [18].

2-Chloro-7-nitrobenzo-2-oxa-1,3-diazol (NBD-CL) has been proved to be a useful and sensitive analytical derivatizing agent for spectrophotometric analysis of pharmaceuticals bearing a primary or secondary amino group [19-34]. The applications of NBD-CL for determination of pharmaceutical bearing amine group have been reviewed by Elbashir et al., [35-36].

The reaction between NBD-Cl and finasteride has not been investigated yet. Therefore, the present study was devoted to investigate the reaction between NBD-Cl and FNS, and utilize this color reaction in the development of simple rapid spectrophotometric method for determination of finasteride in its dosage form. 


\section{Apparatus}

Absorbance was carried out by using a Double beam UV-Visible spectrophotometer model Shimadzu 1800 with quartz cells of $1.0 \mathrm{~cm}$ optical path length, $\mathrm{pH}$ meter was used for $\mathrm{pH}$ measurements, Analytical Balance (Sartorius) and ultrasonic bath (Wise clean laboratory instrument).

\section{MATERial AND REAGENT}

The solvent (methanol) used in this work were of HPLC grade, and distilled water.

Pure drugs and pharmaceutical Tablets: Finasteride standard (Tabuk pharmaceutical industries company Ltd, Khartoum Bahri, Sudan) were obtained and used as received; its purity was $100.19 \%$ with water content $0.20 \%$, The commercial tablets were obtained from commercial sources in the local Pharmacy - Finiscar Tablets 5 mg Batch No: D223,

Reagent: 2-Chloro-7-nitrobenzo-2-oxa-1, 3-diazol (NBD-CL) solution of $0.4 \%$ (w/v) was prepared by dissolving $0.4 \mathrm{~g}$ in methanol, transferred into a $100 \mathrm{~mL}$ volumetric flask and diluted to the mark with methanol and mixed well.

Buffer: Buffer solution of $\mathrm{pH} 11.0$ was prepared by solution of $0.1 \mathrm{M}$ disodium hydrogen phosphate adjusted to $\mathrm{pH} 11.0$ with $1.0 \mathrm{M}$ sodium hydroxide.

\subsection{Stock Standard Solution of Finasteride $(1000 \mu \mathrm{g} / \mathrm{mL})$}

An accurately $100 \mathrm{mg}$ of finasteride standard was dissolved in a mixture of equal volume of methanol and distilled water, transferred into $100 \mathrm{~mL}$ volumetric flask, diluted to the mark with same solvent and mixed well. This stock solution was further diluted to obtain working solutions in the range of $25-75 \mu \mathrm{g} / \mathrm{mL}$.

Determination of finasteride in dosage forms: For preparation of sample solution, 20 Tablets were weighed and powdered then a quantity of powder equivalent to 1.0 tablet $(5 \mathrm{mg})$ of finasteride was transferred into $10 \mathrm{~mL}$ volumetric flask, dissolved in equal volume of methanol and distilled water and completed to the mark with the same solvent to obtain concentration $500 \mu \mathrm{g} / \mathrm{mL}$.

\subsection{Procedure}

A $1.0 \mathrm{~mL}$ of $500 \mu \mathrm{g} / \mathrm{mL}$ of finasteride was transferred into $10 \mathrm{~mL}$ volumetric flask; $1.0 \mathrm{~mL}$ of NBD$\mathrm{CL}$ was added and followed by $1.5 \mathrm{~mL} \mathrm{pH} 11.0 \quad \mathrm{Na}_{2} \mathrm{HPO}_{4}$ buffer solution. The reaction was completed to volume with distilled water, and the resulting solution was measured at $467 \mathrm{~nm}$ against reagent blank treated similarly.

\subsection{Job's method}

The Job's method of continuous variation was employed. Master equimolar $\left(1 \times 10^{-3} \mathrm{M}\right)$ aqueous solution of finasteride and NBD-CL were prepared. Series of $10 \mathrm{~mL}$ portions of the master solution of finasteride and NBD-CL were made up comprising different complementary proportions $(1: 9, \ldots 9: 1$, inclusive) in $10 \mathrm{~mL}$ volumetric flask containing $1.5 \mathrm{ml}$ of buffer solution $(\mathrm{pH}=11.0)$. The solution was further manipulated as described under the general recommended procedures.

\section{RESUltS AND DiscuSSION}

\subsection{Absorption spectra}

The absorption spectrum of finasteride was recorded against water (Figure 1); it was found that finasteride exhibits a maximum absorption peak $\left(\lambda_{\max }\right)$ at $201 \mathrm{~nm}$. Because of highly blue shifted $\lambda_{\max }$ of finasteride, its determination in the dosage form based on the direct measurement of its absorption for ultraviolet is susceptible to potential interferences from the common excipients. Therefore, derivatization of finasteride red-shifted light-absorbing derivative was necessary. The reaction between finasteride and NBD-CL was performed, and the absorption spectrum of the product was recorded against reagent blank (Figure 1). It was found that the product is brown colored exhibiting $\lambda_{\max }$ at $467 \mathrm{~nm}$, and the $\lambda_{\max }$ of NBD-CL was $344 \mathrm{~nm}$. The $\lambda_{\max }$ of finasteride - NBD-CL derivative was red-shifted, eliminating any potential interference. Therefore, the measurements were carried out at $467 \mathrm{~nm}$. 


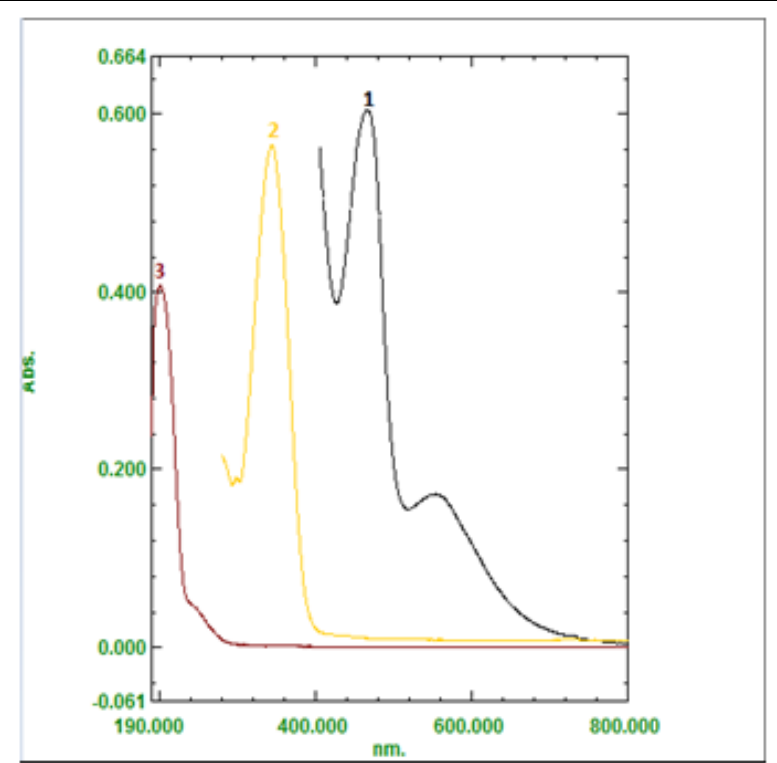

Figure1. (3) Absorption spectra of finasteride $(15 \mu \mathrm{g} / \mathrm{ml})$ against a mixture of methanol and water blank, (2) NBD-CL $(0.001 \%(w / v)$ against methanol blank, (1) the reaction product of finasteride with NBD-CL against reagent blank

\subsection{Optimization of the reaction conditions}

The study and development of the method for the determination of FNS in pure and pharmaceutical formulations, was performed to optimization of the experimental conditions in order to achieve both maximum sensitivity and selectivity. This step comprised the investigation of the influence of the $\mathrm{pH}$, buffer volume, NBD-CL concentration and evaluation of the time required to complete the reaction.

\subsection{Effect of $\mathrm{pH}$}

The influence of $\mathrm{pH}$ on the absorbance of the result of reaction between Finasteride and NBD-CL was investigated in the range of 8.0-13.0, the absorbance of the solution increases up to $\mathrm{pH} 11.0$ and then decrease as shown in Figure 2. At $\mathrm{pH}$ 11.0, the absorbance reaches its maximum; this was possibly due to the existence of the amino group of finasteride in the form of hydrochloride salt, which facilitate nucleophilic substitution capability. As the $\mathrm{pH}$ increased, the readings increased dramatically, at $\mathrm{pH}$ values more than 11.0 , a decrease in the absorption occurred. This was attributed probably to the increase in the amount of hydroxide ion that increases the rate of the backward the reaction of finasteride with NBD-CL.

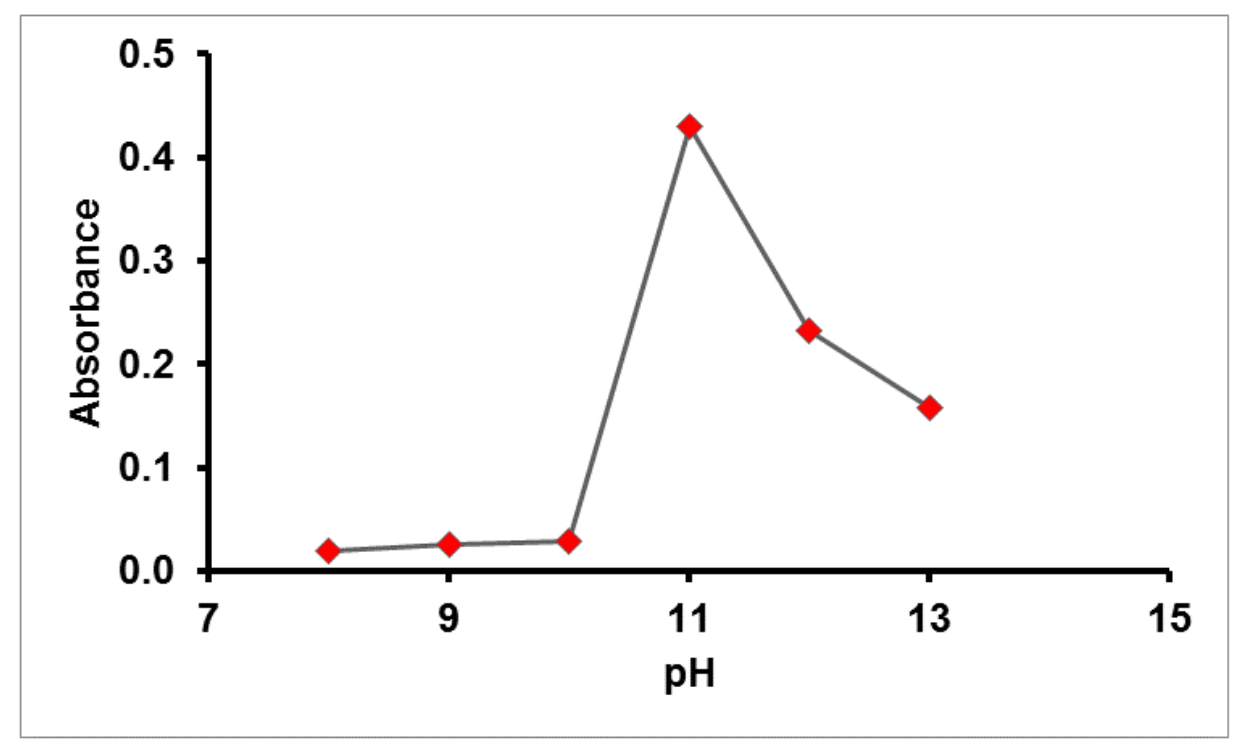

Figure2. Effect of $\mathrm{pH}$ on the reaction of finasteride with $\mathrm{NBD}$-CL, $1 \mathrm{~mL}$ of finasteride $(500 \mu \mathrm{g} / \mathrm{mL}), 1 \mathrm{~mL}$ buffer solution ( $\mathrm{pH} 11), 1 \mathrm{~mL} \mathrm{NBD-CL}(0.4 \mathrm{w} / \mathrm{v} \%)$, reaction time: $25 \mathrm{~min}$ 


\subsection{Effect of amount of the buffer}

Keeping $\mathrm{pH}$ at 11.0, the effect of amount of buffer solution on the absorbance of product was also studied. It shows that the absorbance of product enhances rapidly with the rise of amount of buffer solution. Increasing the amount of the buffer in more products up to an amount of $1.5 \mathrm{~mL}$, after which the absorbance remained almost constant Therefore, the amount of $1.5 \mathrm{~mL}$ buffer solution was selected to ensure the highest absorbance of product 1, as shown in Figure 3.

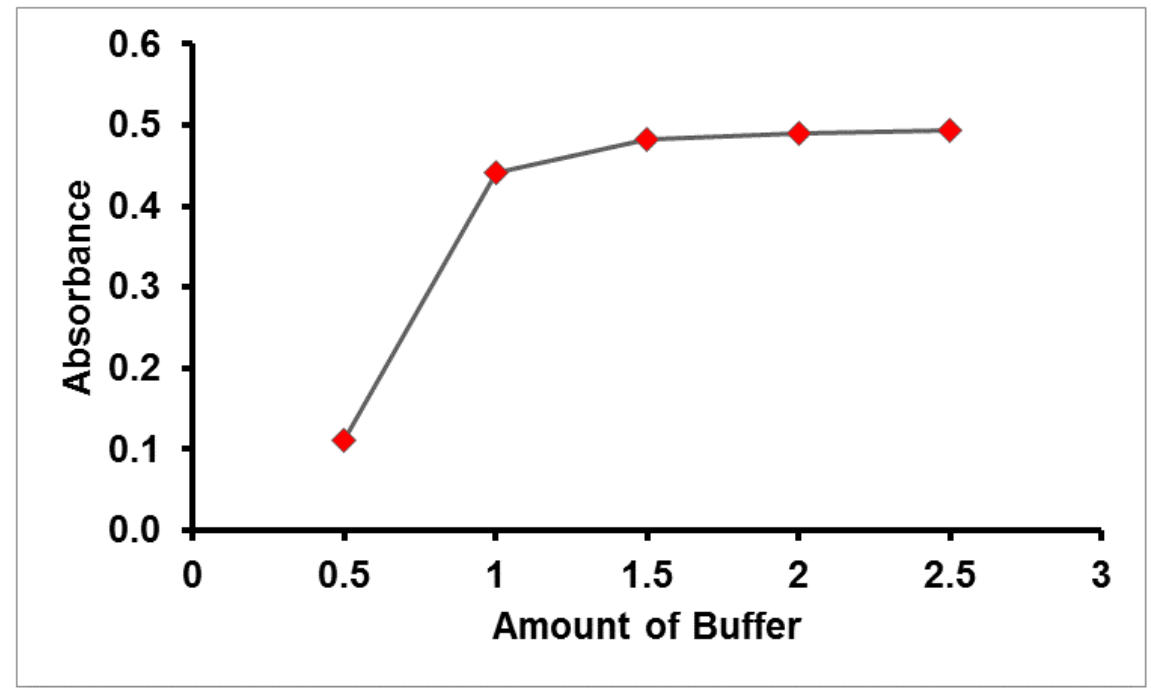

Figure3. Effect of amount of the buffer on the reaction of finasteride with NBD-CL, $1 \mathrm{~mL}$ of finasteride $\quad(500$ $\mu \mathrm{g} / \mathrm{mL}), 1 \mathrm{~mL} \mathrm{NBD}-\mathrm{CL}(0.4 \mathrm{w} / \mathrm{v} \%)$, reaction time: $25 \mathrm{~min}$

\subsection{Effect of NBD-Cl concentration}

The effect of NBD-CL concentration was studied over the range $0.2-0.6 \%(\mathrm{w} / \mathrm{v})$ as shown in Figure 4. The highest absorption intensity was attained at NBD-CL concentration of $0.4 \%(\mathrm{w} / \mathrm{v})$, and higher concentration of NBD-Cl leads to a decrease in the absorbance.

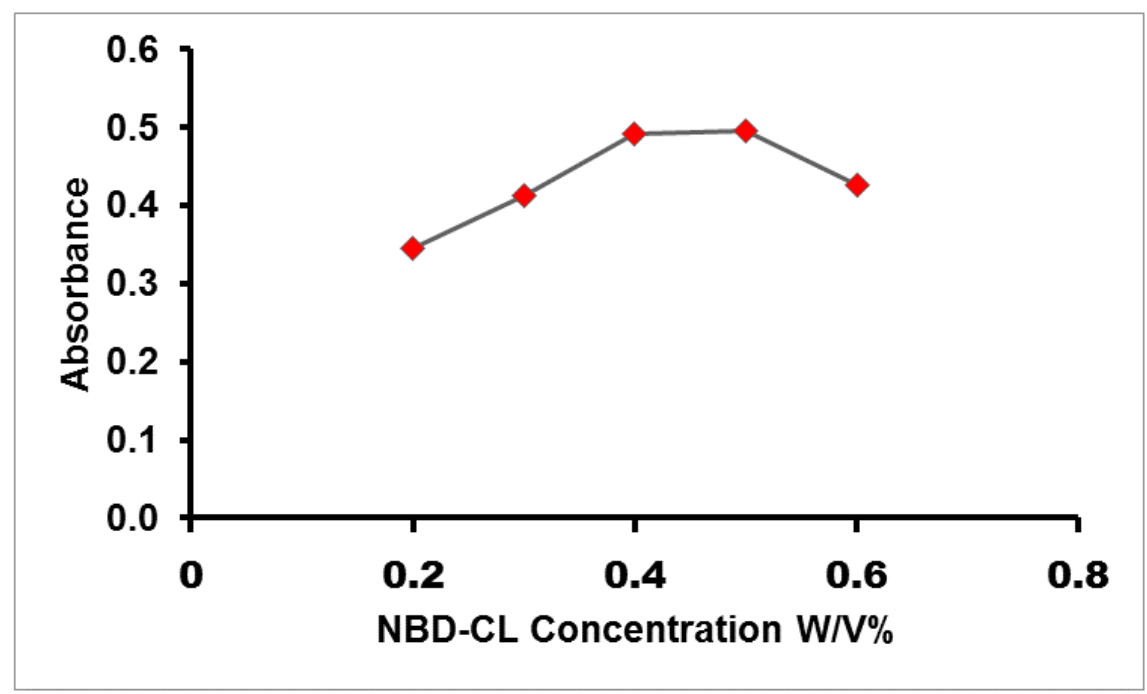

Figure4. Effect of NBD-CL concentration on the reaction of finasteride with $N B D-C L, 1 \mathrm{~mL}$ of finasteride $(500 \mu \mathrm{g} / \mathrm{mL}), 1.5 \mathrm{~mL}$ buffer solution ( $\mathrm{pH} 11.0$ ), reaction time:25 $\mathrm{min}$

\subsection{Effect of time}

The absorbance of product 1 was determined at different time. Keeping other conditions unchanged, the absorbance of the product 1 was measured after standing for different time periods at $25^{\circ} \mathrm{C}$. The results show that finasteride react with NBD-CL at $25^{\circ} \mathrm{C}$ and the absorbance begins to increase instantly and becomes constant after $20 \mathrm{~min}$., and a longer reaction time was not necessary (Figure 5).

From the above experiments, the optimized conditions used for the assay were: $\mathrm{pH}$ 11.0, NBD-CL concentration $0.4 \% \mathrm{w} / \mathrm{v}$, volume of the buffer $1.5 \mathrm{~mL}$, reaction time $20 \mathrm{~min}$ and temperature $25^{\circ} \mathrm{C}$. 


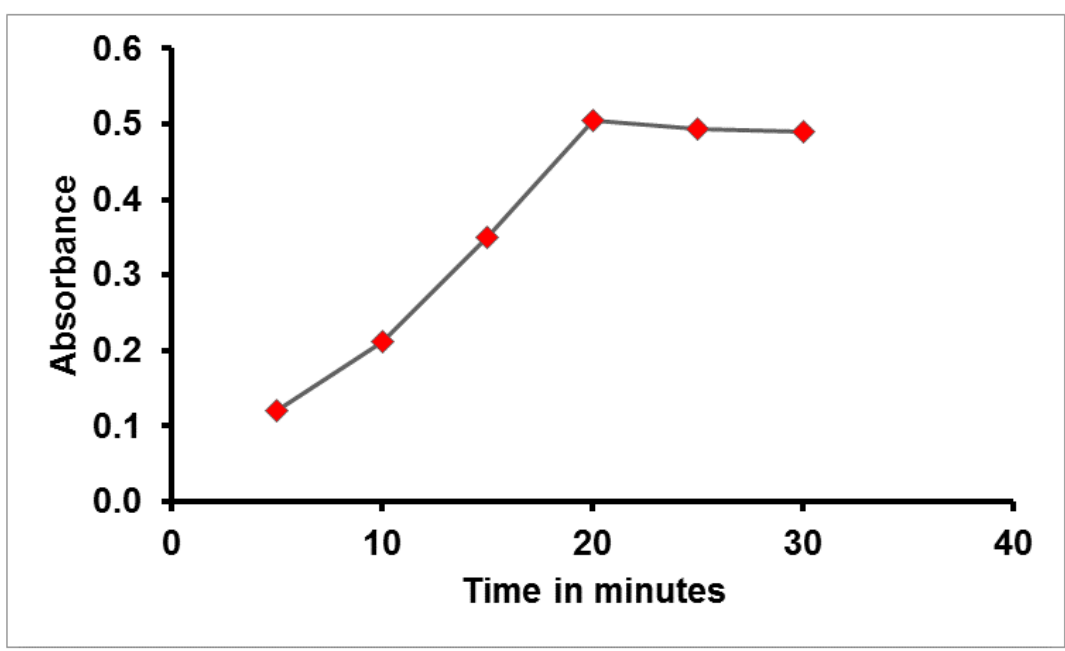

Figure5. Effect of standing time on the reaction of finasteride with $\mathrm{NBD}$-CL, $1 \mathrm{~mL}$ of finasteride $(500 \mu \mathrm{g} / \mathrm{mL})$, $1.5 \mathrm{~mL}$ buffer solution ( $\mathrm{pH} 11.0), 1 \mathrm{~mL} \mathrm{NBD-CL}(0.4 \mathrm{w} / \mathrm{v} \%)$

\section{VALIDATION OF METHOD}

The validity of the methods was tested regarding to linearity, limit of detection (LOD), limit of quantification (LOQ), accuracy, precision and robustness according to the International Conference on Harmonization (ICH) guidelines [37].

\subsection{Linearity, Limit of Detection (LOD), Limit of Quantification (LOQ)}

The linearity was evaluated by linear regression analysis determined by constructing seven concentrations of finasteride, in the range of $25-75 \mu \mathrm{g} / \mathrm{mL}$, which was calculated by the least square regression method to calculate the calibration equation and the correlation coefficient. The calibration curves were constructed by plotting concentration versus absorbance, using linear regression analysis.

The regression equation for the results was $y=0.010489524 \mathrm{x}-0.012190476(\mathrm{r} 2=0.999)$, where $\mathrm{y}$ is the absorbance at $467 \mathrm{~nm}$, $\mathrm{x}$ is the concentration of finasteride in $\mu \mathrm{g} / \mathrm{mL}$ in the range of $25-75 \mu \mathrm{g} / \mathrm{mL}$, and $r$ is correlation coefficient (Table 1).

The limit of detection (LOD) and limit of quantification (LOQ) were determined according to the following formula $\mathrm{LOD}=3.3 \times \mathrm{SDa} / \mathrm{b}$, and $\mathrm{LOQ}=10 \times \mathrm{SDa} / \mathrm{b}, \mathrm{SDa}$ is the standard deviation of the blank, $\mathrm{b}$ is the slope. The LOD and LOQ were found to be 0.17 and $0.52 \mu \mathrm{g} / \mathrm{mL}$, respectively (Table 1).

Table1. Parameters for the performance of the proposed method

\begin{tabular}{|l|l|}
\hline Parameter & value \\
\hline Measurement wavelength $(\mathrm{nm})$ & 467 \\
\hline Linear range $(\mu \mathrm{g} / \mathrm{mL})$ & $25-75$ \\
\hline Intercept & 0.012190476 \\
\hline Standard deviation of the Blank & 0.0005 \\
\hline Slope & 0.010489524 \\
\hline Correlation coefficient $\left(\mathrm{r}^{2}\right)$ & 0.999 \\
\hline Limit of detection, LOD $(\mu \mathrm{g} / \mathrm{mL})$ & 0.17 \\
\hline Limit of quant., LOQ $(\mu \mathrm{g} / \mathrm{mL})$ & 0.52 \\
\hline
\end{tabular}

\subsection{Accuracy}

The accuracy of the proposed method was carried out by applying standard addition technique. A different amount of standard solution was added to a known concentration of the drug sample. The average percent recoveries obtained in range 99.8-103.9\% Table 2 .

Table2. The accuracy of the proposed method was carried out by applying 3 different concentrations of finasteride drug from linear range

\begin{tabular}{|l|l|l|l|}
\hline Sample No. & Sample content $(\mu \mathrm{g} / \mathrm{mL})$ & Amount found & Recovery \% \\
\hline 1 & 30 & 31.16 & $103.87 \pm 0.47$ \\
\hline 2 & 40 & 40.19 & $100.46 \pm 1.37$ \\
\hline 3 & 60 & 59.89 & $99.81 \pm 1.39$ \\
\hline
\end{tabular}




\subsection{Precision}

Precision of the assay was studied by the repetition of the assays on 2 different days. The relative standard deviation (RSD) of inter-mediate precision and accuracy were less than $2.0 \%$, confirming adequate precision of the developed analytical method. The results are shown in Table 3.

Table3. Intermediate precision of proposed method was carried out by applying concentration of finasteride drug within two days

\begin{tabular}{|l|l|l|}
\hline \multicolumn{3}{|c|}{ Assay \%+RSD\% } \\
\hline Dosage form & Day 1 & Day 2 \\
\hline $5 \mathrm{mg} \mathrm{Finiscar}$ & $100.39+1.63$ & $100.82+0.95$ \\
\hline
\end{tabular}

\subsection{Robustness}

Robustness was examined by evaluating the influence of small variation in the method variables on its analytical performance. In these experiments, one parameter was changed whereas the others were kept unchanged, and the recovery percentage was calculated each time.

It was found that variation in the NBD-CL concentration of $0.4 \pm 0.02 \%(\mathrm{w} / \mathrm{v})$, time $(20 \pm 2 \mathrm{~min})$ and $\mathrm{pH}(11.0 \pm 0.2)$ and wavelength $(467 \pm 2 \mathrm{~nm})$ did not significantly affect the procedures. Recovery values were recorded in table 4 . This indicated the reliability of the proposed method to routine application for the analysis of finasteride.

Table4. Influence of small variation in the assay condition on the analytical performance of the proposed spectrophotometric method for determination of Finasteride using NBD-CL reagent

\begin{tabular}{|l|l|}
\hline Parameter & \multicolumn{1}{l|}{ Recovery \% } \\
\hline Recommended conditions & 100.39 \\
\hline NBD-CL concentration $(\%, w / v)$ & 100.71 \\
\hline 0.38 & 98.46 \\
\hline 0.42 & 100.64 \\
\hline Buffer solution $(\mathrm{pH})$ & 101.16 \\
\hline 10.8 & 99.74 \\
\hline 11.2 & 101.16 \\
\hline Reaction time $(\min )$ & 100.39 \\
\hline 18 & 99.23 \\
\hline 22 & \multicolumn{2}{|l}{} \\
\hline wavelength(nm) & \\
\hline 465 & \\
\hline 469 & \\
\hline
\end{tabular}

\subsection{Reaction mechanism}

It has been reported that NBD -Cl could react with amino group of Secondary amine derivative. Similarly, amino group of finasteride, taking on nucleophilicity due lone electron pair of nitrogen atom, trend to attack on the electron-deficient center in NBD-Cl, At the same time, it has been proved that the composition of product 1 is 1:2 of Finasteride and NBD-Cl (Figure 6). So it is concluded that amino group of finasteride react with NBD-Cl to form brown adduct. The reaction equation is shown in Figure 7.

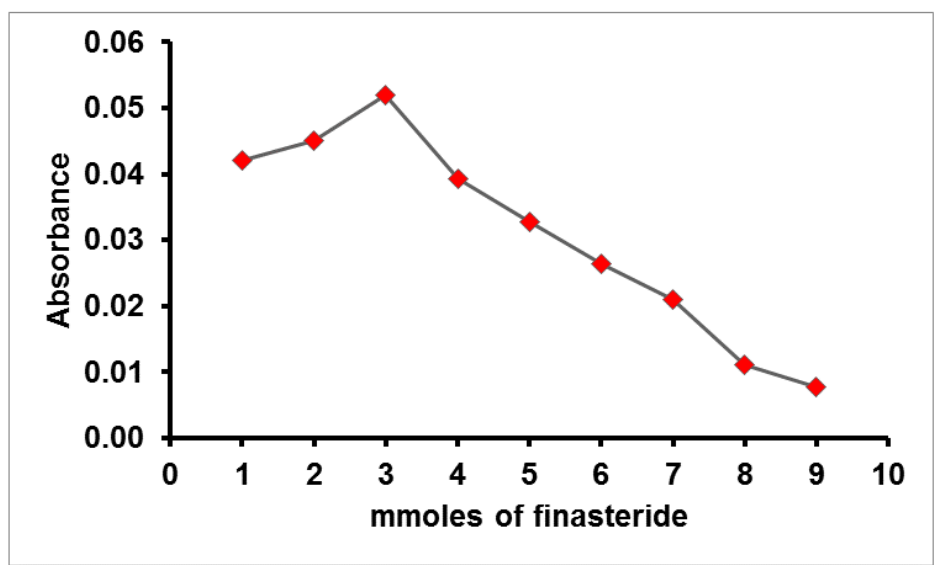

Figure6. The continuous variation plot for the stoichiometry of the reaction of finasteride with NBD-CL 

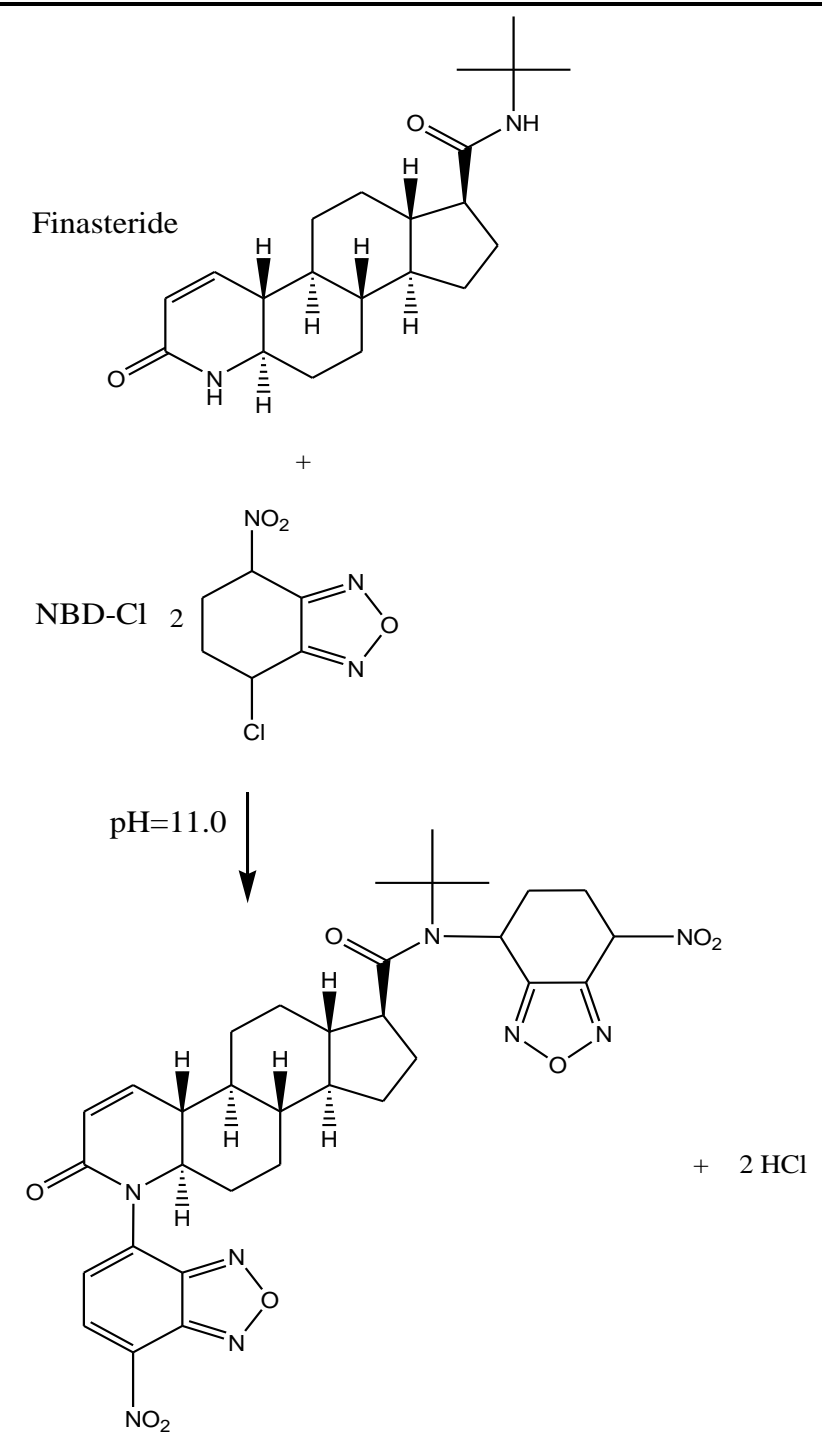

Figure7. Reaction mechanism of Finasteride with $\mathrm{NBD}-\mathrm{Cl}$

\subsection{Application of the proposed method to analysis of finasteride dosage form:}

Finasteride tablets were subjected to the analysis by the proposed method as well as with the official HPLC method (United States Pharmacopeia) and the results were statistically compared with each other. The label claim percentage was $100.39 \pm 1.63$ (Table 5). Statistical analysis of the results reveals that at the $95 \%$ level of confidence, the calculated $\mathrm{t}$ - and F-values indicate the proposed method to be as precise and accurate as the standard method, the proposed method has the advantage of being virtually free from interferences by excipients.

Table5. Analysis of finasteride containing dosage forms by the proposed and official HPLC methods (United States Pharmacopoeia)

\begin{tabular}{|l|l|l|l|l|}
\hline Dosage form & \multicolumn{2}{|l|}{ Recovery \% +RSD (n =5) } & t-value & f-value \\
\hline & Official & Proposed & & \\
\hline $\begin{array}{l}\text { Finiscar 5mg } \\
\text { Batch no: D223 }\end{array}$ & $102.00 \pm 0.46$ & $100.39 \pm 1.63$ & 1.74 & 12.05 \\
\hline
\end{tabular}

The tabulated values for $t$ and f at $95 \%$ confidence limit are 3.18 for $t$ and 18.51 for $f$ for Finiscar 5mg Batch no: $D 223$

\section{Conclusion}

A novel, rapid, and simple method for evaluation of the finasteride in pharmaceutical formulation has been developed and validated. The results of the validation studies show that the method is simple, reliable, specific, accurate, reproducible, and highly sensitive. The present paper described the evaluation of $\mathrm{NBD}-\mathrm{Cl}$ as analytical reagents in the development of simple spectrophotometric 
method, for the determination of finasteride in dosage forms. the validated method has advantages over pharmacopeia method because it is does not need necessitate any expensive apparatus; therefore the proposed method can be used advantageously as a routine method for the determination of finasteride in quality control and industry, the method may be applied to the determination of other Secondary amine derivatives as well.

\section{REFERENCES}

[1] Current Index of Medical Specialities (CIMS), ( 2005) updated prescriber's Hand Book, CMP Media India Pvt.LTd.,Bangalore, India.,p 288.

[2] Schmidt, L.J. Tindall, D.J. (2011) Steroid 5 -reductase inhibitors targeting BPH andprostate cancer, J. Steroid Biochem. Mol. Biol. 125:32-38.

[3] Cha E.K, Shariat S.F (2011) the use of $5 \alpha$-reductase inhibitors for the prevention and treatment of prostate cancer, Eur. Urol. 59:515-517.

[4] Lucas J.K (1995) Finasteride in the treatment of hirsutism, J. Womens Health 4:655-661.

[5] Mella J.M, Perret M.C, Manzotti M, et al (2010) Efficacy and safety of finasteride therapy for androgenetic alopecia, Arch. Dermatol. 146:1141-1150.

[6] Tully A.S, Schwartzenberger J, Studdiford J (2010) Androgenic Alopecia, J. MensHealth 7:270-277.

[7] Yamazaki M, Miyakura T, Uchiyama M, et al. (2011) Oral finasteride improved the quality of life of androgenetic alopecia, J. Dermatol.38:773-777.

[8] Almeida H.M, Marques C.H. (2011) Physicochemical characterization of finasteride: PEG 6000 and finasteride:Kollidon K25 solid dispersions, and finasteride:-cyclodextrin inclusion complexes, J. Incl. Phenom. Macro. 70: 397-406.

[9] Sağlik S, Tatar Ulu S (2006) Development and validation of a new gas flame ionization detector method for the determination of finasteride in tablets. Anal Biochem 352: 260-264.

[10] Guarna A, Danza G, Bartolucci G, et al. (1995) Synthesis of 5,6,6-[2H3] finasteride and quantitative determination of finasteride in human plasma at picogram level by an isotopedilution mass spectrometric method. J Chromatogr B Biomed Appl 674: 197-204.

[11] Constanzer ML, Chavez CM, Matuszewski BK (1994) Picogram determination of finasteride in human plasma and semen by high-performance liquid chromatography with atmosphericpressure chemical-ionization tandem mass spectrometry. J Chromatogr B Biomed Appl 658: 281-287.

[12] Matuszewski BK, Constanzer ML, Chavez-Eng CM (1998) Matrix effect in quantitative LC/MS/MS analyses of biological fluids, a method for determination of finasteride in human plasma at picogram per milliliter concentrations. Anal Chem 70: 882-889.

[13] Demir H, Cucu A, Sakarya S (2006) Determination of finasteride in the tablet form by liquid chromatography and its analytical method validation. Anal Chim Acta 557: 252-255.

[14] Amer SM (2003) Polarographic behavior and determination of finasteride. Farmaco 58: 159163.

[15] Alvarez-Lueje A, Brain-Isasi S, Núñez-Vergara LJ, et al. (2008) Voltammetric reduction of finasteride at mercury electrode and its determination in tablets. Talanta 75:691-696.

[16] Ilango K, Valentina P, Lakshmi KS (2002) Spectrophotometric determination of Finasteride in tablet formulation. Indian J Pharm Sci 64: 174-175.

[17] Ahmed SM, Elbashir AA (2015) Development and Validation of Spectrophotometric Method for Determination of Finasteride in Pharmaceutical Formulation Using 1,2Naphthoquine-4-sulfonate (NQS),J Anal Bional Tech. 6:247.

[18] Ulu ST (2007) A new spectrophotometric method for the determination of finasteride in tablets. Spectrochim Acta A Mol Biomol Spectrosc 67:778-783.

[19] Elbashir, A.A. Krieger, S. Schmitz, O.J. (2014) Simultaneous determination of polyamines and acetylpolyamines in human urine by capillary electrophoresis with fluorescence detection, Electrophoresis 35 (4): 570-576

[20] Abdel RahmanS.T.,Elbashir, A.A.El-Mukhtar M. et al.(2016)Application of Spectrophotometric Methods for the Determination of Thiamine (VB1) in Pharmaceutical Formulations Using 7-Chloro-4-Nitrobenzoxadiazole (NBD-Cl), J Analytical \& Pharmaceutical Research, 2: $2-6$. 
[21] Basheir, B.E.A. Elbashir, A.A. (2015) Spectrophotometric Method for Determination of LDopa in Pharmaceutical Formulation Using 7-Cholor- 4-Nitrobenzoxadiazole (NBD-CL) as A Chromogenic Reagent, European Journal of Pharmaceutical and Medical Research, ejpmr, ,2(1): 304-316.

[22] Mohammed, T.O. Elbashir, A.A. (2015) Spectrophotometric Method for Determination of Gabapentin in Pharmaceutical Formulation by Derivatization with 4-Chloro-7-Nitrobenzo-2Oxa-1, 3-Diazole (NBD-Cl), Int J Drug Dev \& Res, 7:1-4

[23] Taha EA, Salama NN, Fattah L (2005) Spectrofluorimetric and spectrophotometric stabilityindicating methods for determination of some oxicams using 7-chloro-4-nitrobenz-2-oxa1,3-diazole (NBD-CL). Chem Pharm Bull 54: 653-658.

[24] El-Enany N, El-Sherbiny D, Belal F (2007) Spectrophotometric, spectrofluorometric and HPLC determination of desloratadine in dosage forms and human plasma. Chem Pharm Bull 55: 1662-1670.

[25] Saleh HM, EL-Henawee MM, Ragab GH, et al. (2007) Utility of NBD-CL for the spectrophotometric determination of some skeletal muscle relaxant and antihistaminic drugs. Spectrochim Acta A 67: 1284-1289.

[26] Shehata MA, El-Sayed GM, Abdel-Fattah LE (2006) Utilization of 4-chloro-7-nitro-2,1,3benzoxadiazole (NBD-CL) for kinetic spectrophotometric assay of befunolol hydrochloride in its pharmaceutical formulation. J AOAC Int 89: 646-650.

[27] Olojo RO, Xia RH, Abramson JJ (2005) Spectrophotometric and fluorometric assay of superoxide ion using 4-chloro-7-nitrobenzo-2-oxa-1,3-diazole. Anal Biochem 339: 338-344.

[28] Olgun N, Erturk S, Atmaca S (2002) Spectrofluorimetric and spectrophotometric methods for the determination of vigabatrin in tablets. J Pharm Biomed Anal 29: 1-5.

[29] Onal A, Kepekci SE, Oztunc A (2005) Spectrophotometric methods for the determination of antidepressant drug paroxetine hydrochloride in tablets. J AOAC Int 88: 490-495.

[30] El-Emam AA, Hansen SH, Moustafa MA, et al. (2004) Determination of lisinopril in dosage forms and spiked human plasma through derivatization with 7-chloro-4-nitrobenzo-2-oxa1,3-diazole (NBD-CL) followed by spectrophotometry or HPLC with fluorimetric detection. J Pharm Biomed Anal 34: 35-44

[31] Amin AS, Ragab GH, Saleh H (2002) Colorimetric determination of $\beta$-blockers in pharmaceutical formulations. J Pharm and Biomed Anal 30: 1347-1353.

[32] Abdellatef HE (2002) Kinetic spectrophotometric determination of tramadol hydrochloride in pharmaceutical formulation. J Pharm Biomed Anal 29: 835-842.

[33] Önal A, Sagirli O (2009) A Spectrophotometric and spectrofluorimetric methods for the determination of pregabalin in bulk and pharmaceutical preparation. Spectrochim Acta A 72: 68-71.

[34] Elbashir AA, Alfadil AAB (2013) Development and Validation of Spectrophotometric Method for Determination of Penicillamine (PA) in Pharmaceutical Formulation Using 4Choro-Nitrobenzo-2-Oxa-1, 3-Diazol (NBD-CL). World Journal of Analytical Chemistry 1: $18-22$.

[35] Elbashir AA, Suliman FO, Aboul-Enein HY (2011) the application of 7-chloro-4-nitrobenzoxadiazole (NBD-CL) for the analysis of pharmaceutical-bearing amine group using spectrophotometry and spectrofluorometry techniques. Appl Spectros Rev 46: 222-241.

[36] Elbashir AA, Suliman FO, Aboul-Enein HY (2011) The Application of 7-Chloro-4-Nitrobenzoxadiazole and 4-Fluoro-7-Nitro-2,1,3 Benzoxadiazole for The Analysis of Amines and Amino Acids Using High-Performance Liquid Chromatography. GU J Sci 24: 679-697.

[37] ICH Expert Working Group (2005) International Conference on Harmonization of Technical Requirements for Registration of Pharmaceuticals for Human Use. Validation of analytical procedures: Text and methodology Q2 (R1). 